\title{
INTENSIFICAÇÃO DA PRODUÇÃO DE OVINOS EM PASTO x SUSTENTABILIDADE
}

\author{
Rafael Eduardo Lourenço Pinê ${ }^{1}$
}

\author{
Rafael Silvio Bonilha Pinheiro²
}

Ramon Cellin Rochetti ${ }^{3}$

\begin{abstract}
RESUMO: No presente trabalho objetivou-se avaliar a produção de matéria seca e o desempenho de borregas em sistema rotacionado de pastejo de Colonião (Panicum maximum cv.), submetido a doses crescentes de nitrogênio. Os tratamentos foram constituídos por 0, 75 e $150 \mathrm{~kg} / \mathrm{ha}$ de nitrogênio na forma de uréia. No final do experimento as borregas foram pesadas e foi possível calcular o ganho de peso no período experimental $(\mathrm{kg})$ e diário $(\mathrm{g})$, o qual foi maior para os animais do tratamento em que não foi adubada a pastagem com uréia (2,5 kg e 44,64g/dia) em relação a pastagem adubada com $150 \mathrm{~kg} / \mathrm{ha}$ nitrogênio $(0,87 \mathrm{~kg}$ e 15,53 g/dia). Conclui-se que a utilização da adubação nitrogenada proporcionou maior quantidade de forragem em relação à pastagem não adubada, portanto há possibilidade do sistema de produção apresentar maior produtividade sem a necessidade de desmatamento de novas áreas.
\end{abstract}

Palavras-chave: Meio ambiente. Pastejo. Produção rural.

\footnotetext{
${ }^{1}$ Zootecnista da FEIS/UNESP - Campus de Ilha Solteira. rafaelpine@zootecnista.com.br ${ }^{2}$ Professor Doutor do Departamento de Biologia e Zootecnia da FEIS/UNESP - Campus de Ilha Solteira. rafaelsbp@bio.feis.unesp.br 32Zootecnista da FEIS/UNESP - Campus de llha Solteira. ramon.rochetti@hotmail.com.br
} 


\section{INTRODUÇÃO}

A produção de ruminantes em regime de pasto no Brasil caracteriza-se ainda pelo extrativismo na maioria dos casos, onde a adoção de tecnologias e uso intensivo em capital restringe-se a um pequeno conjunto de produtores. Tal conduta, na maioria das vezes, determina passivos ambientais relevantes. A perda da capacidade produtiva das pastagens e seus impactos sobre o ambiente, além do comprometimento da sustentabilidade da atividade são facilmente percebidos (BARCELLOS et al., 2008). A dinâmica das alterações macroeconômicas ocorridas na última década exige dos produtores rurais mudanças de comportamento drástico, pressionados pela necessidade de conferir e assegurar maior produtividade e competitividade a seus sistemas de produção. A sociedade também exerce forte pressão no sentido de mudanças dos modelos atuais de exploração, ou melhor de produção animal. Segundo os autores a preservação dos recursos naturais, da biodiversidade e a mitigação dos impactos relacionados às mudanças climáticas globais, decorrentes das alterações no uso da terra, além da qualidade e segurança dos produtos alimentares, fazem parte da pauta de discussões e ações governamentais já há algum tempo.

De acordo com Barcellos et al. (2008) a intensificação dos sistemas de produção pastoris é apontada como uma das alternativas de produção sustentável, minimizando a pressão sobre a abertura de novas áreas para produção agropecuária. Esse modelo, entretanto, deverá ser pautado pelo uso eficiente dos recursos físicos, incluindo a recuperação de áreas antropizadas e degradadas, calcada no aporte de conhecimento e de tecnologias poupadoras de insumos.

É fato que a produção de ruminantes contribui com boa parte dos alimentos consumidos pelos humanos, gerando empregos diretos e indiretos na área urbana e rural, além de impulsionar a cadeia produtiva que tem grande participação na economia de muitas regiões do Brasil e do mundo. As pastagens ocupam dois terços da área agricultável no mundo segundo Paulino e Teixeira (2012). Segundo os autores a baixa fertilidade do solo e o manejo incorreto são apontados como causas principais da 
degradação das pastagens e isto provoca a diminuição no sequestro de carbono que representa uma compensação às emissões de metano e óxido nitroso.

Atualmente a produção animal sustentável tem sido o foco de pesquisa em todo o mundo, frente às mudanças climáticas globais (SILVA et al., 2010). Uma das primeiras tecnologias desenvolvidas visando o uso sustentável baseia-se na manipulação da vegetação para fins pastoris. Esta manipulação permite a oferta de forragem aos animais em períodos onde a mesma seria escassa, e ainda, possibilita a oferta de forragem com teores mais altos de proteína, minimizando a fermentação ruminal de fibra, reduzindo assim a emissão de gases de efeito estufa (SANTOS et al., 2011). O melhoramento genético, tanto de plantas como 0 de animais exóticos quanto de espécies nativas, permitirá o desenvolvimento de novos cultivares e cruzamentos mais produtivos e melhor adaptados nas diferentes regiões do Brasil. Também a utilização de irrigação das pastagens, correção, adubação e manejo adequado do solo permitem maior produtividade e preservação do ambiente.

Ainda muitas propriedades com atividade pecuária apresentam manejo inadequado do solo, das pastagens, dos animais e do gerenciamento da atividade de produção, predispondo em muitos casos à degradação das áreas de pastagens e o aumento dos impactos ao ambiente (falta de cobertura do solo, consequentemente erosão, voçorocas e assim assoreamento de muitos córregos e rios). Nesse cenário, ao qual periodicamente somam-se novas exigências (rastreabilidade, qualidade, segurança alimentar, exigências sanitárias, ambientais e outras demandas), o pecuarista deverá conscientizar-se de que é necessário elevar a produtividade do "recurso terra" para garantir a rentabilidade do empreendimento, visando a redução do custo médio de produção pela diluição dos custos fixos e dos custos de oportunidade do uso do capital (BARCELLOS et al., 2008).

No entanto, o que foi relatado, ainda não é prática na ovinocultura brasileira (a adoção de medidas de sustentabilidade ao ambiente em conjunto com alta produtividade de ovinos em pastagem ainda é pouco estudada). Portanto, há necessidade de pesquisas nesta área em relação à espécie animal que vem sendo destacada nas distintas regiões do Brasil pelo maior consumo de carne. 


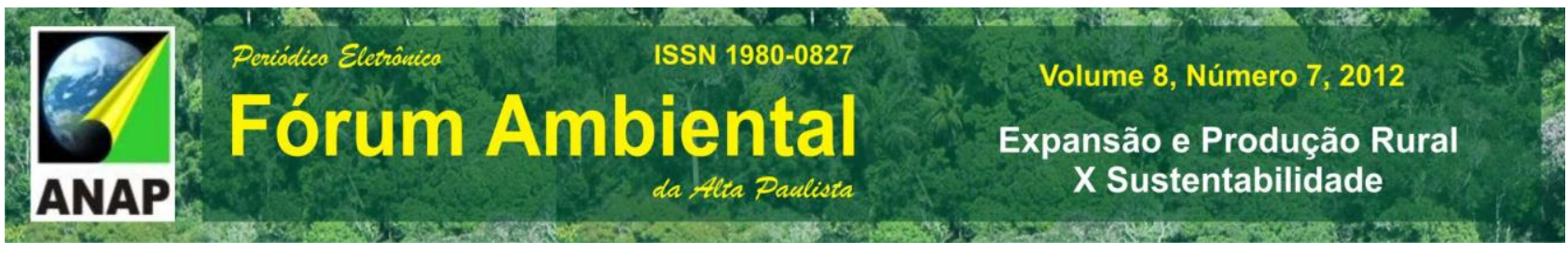

O objetivo deste estudo foi avaliar a produção de matéria seca da forragem e o desempenho de borregas em sistema rotacionado de pastejo de Colonião (Panicum maximum cv.), submetido a doses crescentes de nitrogênio.

\section{MATERIAL E MÉTODOS}

O experimento foi conduzido no Setor de Ovinocultura da Fazenda de Ensino, Pesquisa e Extensão da Faculdade de Engenharia da UNESP do Campus de llha Solteira, SP, no primeiro semestre de 2011, situado numa altitude $347,361 \mathrm{~m}$ e

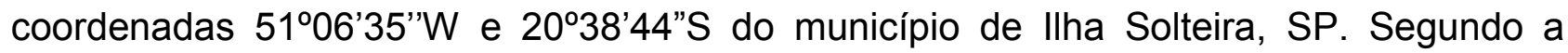
classificação de Köppen, a região possui clima do tipo Aw, definido como tropical úmido, caracterizado por estação chuvosa no verão e seca no inverno, com temperatura, precipitação média anual e umidade relativa médias anuais de $24,5^{\circ} \mathrm{C}, 1.232 \mathrm{~mm} \mathrm{e}$ $64,8 \%$, respectivaemente (HERNANDEZ et al., 1995).

Uma área de $3150 \mathrm{~m}^{2}$ de pastagem de Colonião (Panicum maximum cv.) foi subdividida em nove áreas (piquetes), de $350 \mathrm{~m}^{2}$ cada, as quais foram delimitadas com cerca elétrica com 4 fios a fim de assegurar que os animais permanecessem separados de acordo com cada tratamento. Todos os piquetes tinham bebedouro e saleiro.

Foram utilizadas 28 borregas da raça Santa Inês com idade média de 8 meses e com $33 \mathrm{~kg}$ de peso corporal. Todos os animais foram identificados individualmente, desverminados com anti-helmíntico quando necessário (ovos por grama de fezes maior que 1.000) e distribuídos em três grupos, os quais permaneceram nos respectivos tratamentos experimentais.

Antes do início do experimento foi realizada a análise do solo, a uma profundidade de 0 a $20 \mathrm{~cm}$, e de acordo com a mesma, foram utilizados $192 \mathrm{~kg}$ de cloreto de potássio, 157,5 kg de superfosfato simples e $3 \mathrm{~kg}$ de ácido bórico para correção da fertilidade do solo na área de pastagem. A quantidade de nitrogênio utilizado em cada piquete foi determinada de acordo com os tratamentos experimentais (sem adubação nitrogenada $=$ SAN, com adubação nitrogenada $=$ CAN e com adubação nitrogenada 
moderada $=$ CANM), sendo: $0($ SAN), $75(C A N)$ e $150($ CANM) $\mathrm{kg} / \mathrm{ha}$ de nitrogênio em dose única; cada tratamento apresentou três repetições (Figura 1). A uréia foi aplicada a lanço durante um dia chuvoso.

\begin{tabular}{|c|c|c|c|c|c|c|c|c|}
\hline SAN & CAN & CANM & CAN & CANM & SAN & CANM & CAN & SAN \\
(1 ${ }^{\circ}$ rep. $)$ & $\left(2^{\circ}\right.$ rep. $)$ & $\left(1^{\circ}\right.$ rep. $)$ & $\left(3^{\circ}\right.$ rep. $)$ & $\left(2^{\circ}\right.$ rep. $)$ & $\left(3^{\circ}\right.$ rep. $)$ & $\left(3^{\circ}\right.$ rep. $)$ & $\left(1^{\circ}\right.$ rep. $)$ & $\left(2^{\circ}\right.$ rep. $)$ \\
pasto A & pasto B & pasto A & pasto C & pasto B & pasto C & pasto C & pasto A & pasto B \\
\hline
\end{tabular}

Figura 1 - As borregas do tratamento SAN, CAN e CANM permaneceram 7 dias no pasto A. Os animais do tratamento SAN, CAN e CANM foram transferidos para o pasto $B$ e permaneceram por 7 nesta área. Os animais do tratamento SAN, CAN e CANM foram transferidos para o pasto $\mathrm{C}$ e permaneceram por 7 dias nesta área. A cada 21 dias iniciava um novo ciclo de pastejo na área experimental. Rep. = repetição.

O método de utilização da pastagem foi o de pastejo rotacionado com lotação variável. O ajuste da lotação foi realizado pela técnica "put and take" segundo Mott e Lucas (1952). Os animais de cada tratamento permaneceram em pastos separados. Após 7 dias de permanência no pasto os animais foram manejados para outro pasto, que havia passado por 21 dias de descanso (Figura 1).

Antes da entrada dos animais no pasto, foi determinada a produção de matéria seca. A produção de MS foi determinada de acordo com o método do quadrado, conforme descrito por Gastaldi, (1996). As coletas da pastagem foram realizadas uma vez por semana, obtendo-se três amostragens compostas (amostras de entrada do pasto com $0 \%, 75 \%$ e $150 \%$ de $\mathrm{N} / \mathrm{ha})$. As amostras de forragem foram secas em estufa $\left(65^{\circ} \mathrm{C}\right)$, com ventilação forçada de ar até peso constante. Após a secagem as amostras foram pesadas para obtenção da produtividade de matéria seca da área experimental.

Os animais foram pesados a cada 7 dias para definir a lotação animal, a qual foi em relação a quantidade de MS, disponibilidade de $12 \%$ de forragem na MS por animal dia (considerando-se o consumo de forragem, o pisoteio, a deposição de fezes e de urina e os locais onde os animais se deitam) e o número de dias de pastejo na área. O ganho de peso total no período e o ganho diário de peso foram obtidos pela diferença entre 0 peso corporal final e inicial do experimento. 
Os dados de condições climáticas (temperatura, precipitação pluviométrica e umidade relativa do ar média) do período total experimental foram obtidos pelo Departamento de Fitossanidade, Engenharia Rural e Solos (área de hidráulica e irrigação) da UNESP de Ilha Solteira - SP (Figura 2). Cada período experimental foi de 7 dias, sendo ao total neste estudo 8 períodos. O $1^{\circ}$ período foi do dia 9 a 15 de março, o $2^{\circ}$ período foi do dia 16 a 22 de março, o 3ำ período foi do dia 23 a 29 de março, o 4º período foi do dia 30 de março a 5 de abril, 5ำ período foi do dia 6 a 12 de abril, 6ำ período foi do dia 13 a 19 de abril, $7^{\circ}$ período foi do dia 20 a 26 de abril e $8^{\circ}$ período foi do dia 27 de abril a 3 de maio. Todos os períodos foram realizados no ano de 2011.

O delineamento experimental adotado foi o de blocos ao acaso, composto por três tratamentos (doses de N) e com três repetições (piquetes).

Os dados coletados para cada variável foram submetidos à análise de variância a $5 \%$ de significância, por intermédio do programa estatístico Statistical Analysis System (SAS, 2002). Foram determinadas equações de regressão linear simples

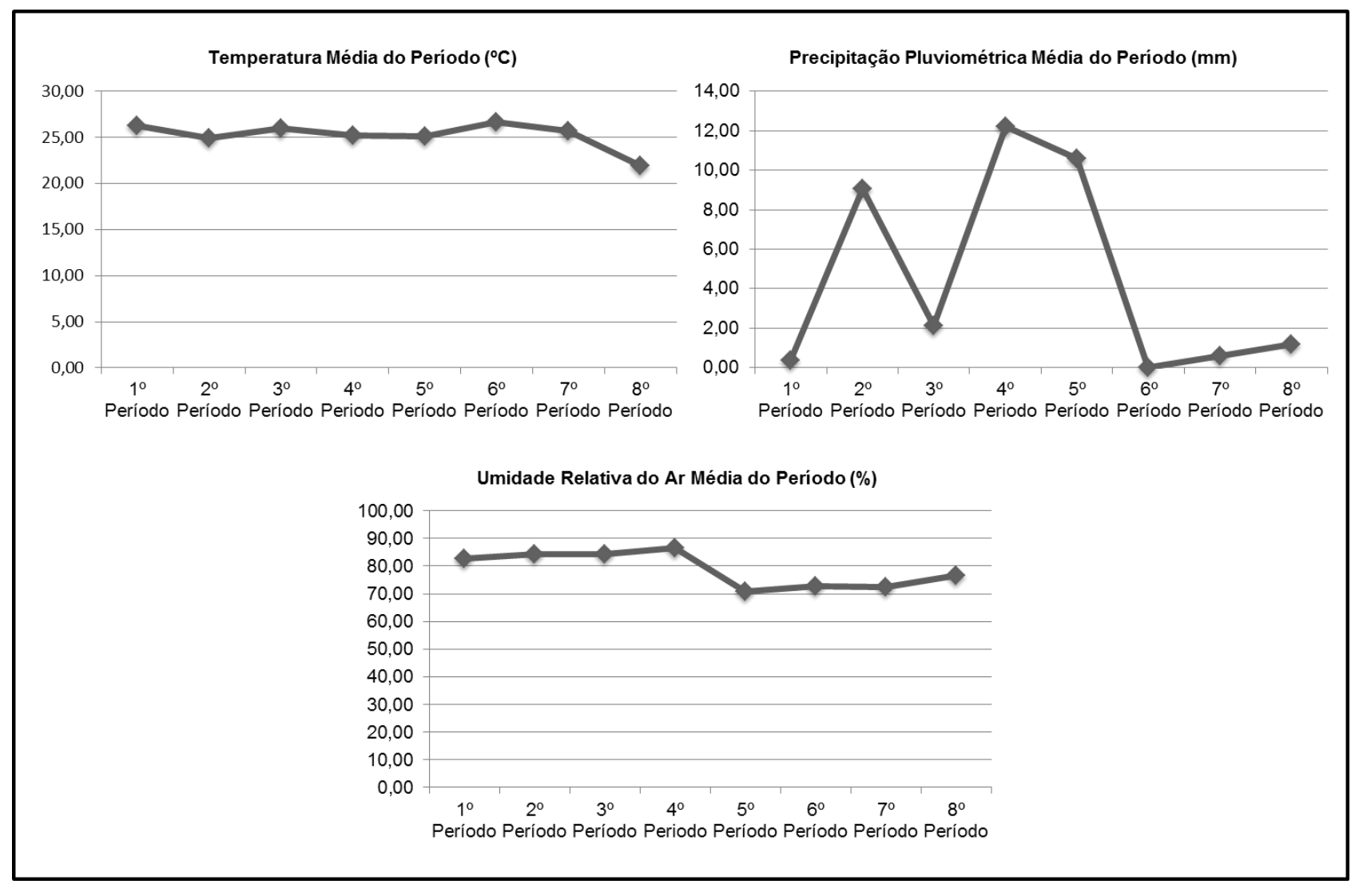

VIII Fórum Ambiental da Alta Paulista, v. 8, n. 7, 2012, p. 55-67. 
Figura 2 - Condições climáticas (temperatura, precipitação pluviométrica e umidade relativa do ar média) do período experimental.

\section{RESULTADOS E DISCUSSÃO}

A área de pastagem que não foi adubada com fonte nitrogenada apresentou produção de matéria verde e seca de $3.497,49$ e $1.128,45 \mathrm{~kg} / \mathrm{ha}$ respectivamente, inferiores aos das pastagens adubadas com $75 \mathrm{~kg} / \mathrm{ha}(6.102,95$ e $1.623,99 \mathrm{~kg} / \mathrm{ha})$ e com $150 \mathrm{~kg} / \mathrm{ha}$ (6.309,18 e 1.543,19 kg/ha). De acordo com Werner et al. (2001) a utilização de adubação nitrogenada propicia aumento da produção de forragem como um todo, especialmente de colmos, que apresenta maior peso de massa. Em relação à produção de matéria verde e seca da pastagem de Colonião adubada com diferentes doses (75 e $150 \mathrm{~kg} / \mathrm{ha}$ ) de uréia não houve diferença significativa entre as quantidades utilizadas (Figura - 3). De acordo com relatado por Barcellos et al. (2008) a maior produtividade das pastagens pode contribuir para a melhoria da qualidade do solo e para a redução de eventuais impactos do ambiente. Também para o maior desempenho por animal, o qual pode reduzir a emissão de gases causadores do efeito estufa por unidade de produto produzido, o que poderá minimizar possíveis barreiras não tarifárias à produção pecuária brasileira. 

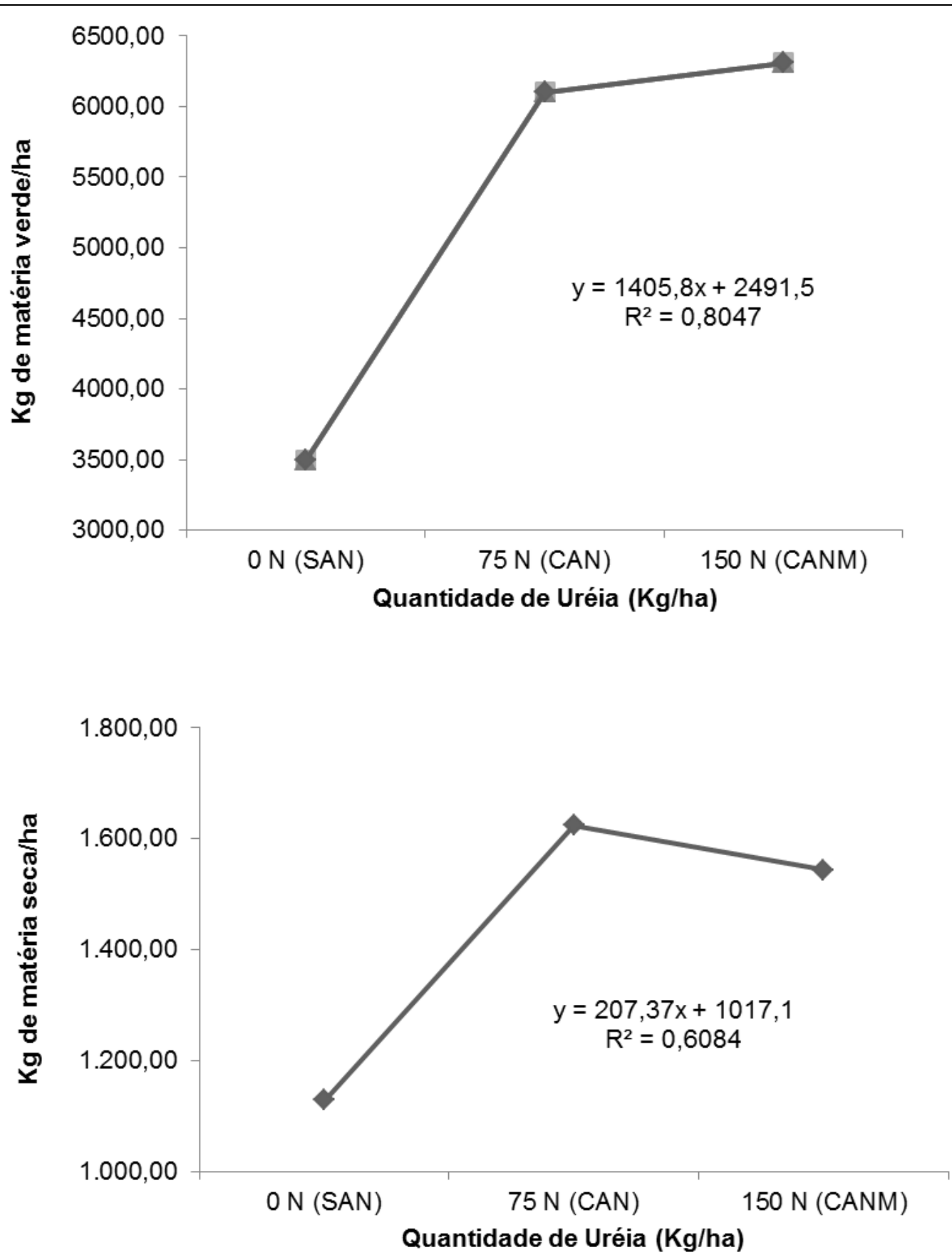

Figura 3 - Produção de matéria verde e seca da pastagem de Colonião (Panicum maximum cv.), submetida a doses crescentes de nitrogênio $(0 \mathrm{~kg} / \mathrm{N} / \mathrm{ha}, 75 \mathrm{~kg} / \mathrm{N} / \mathrm{ha}$ e $150 \mathrm{~kg} / \mathrm{N} / \mathrm{ha})$.

A adubação nitrogenada aumenta a massa de forragem, a taxa de lotação e a produção animal por área em pastagem de Brachiaria decumbens cv. Basilisk manejada sob lotação contínua com taxa de lotação variável segundo Moreira et al. (2011), estando 
de acordo com este estudo em relação à produção de forragem produzida por hectare (Figura 3).

O número de animais na pastagem não adubada com nitrogênio foi de 4 animais em média durante o período experimental enquanto o número de ovinos da pastagem adubada com $75 \mathrm{~kg} / \mathrm{ha}$ foi de 9 animais em média e a adubada com $150 \mathrm{~kg} / \mathrm{ha}$ de nitrogênio foi de 12 borregas em média. O número de ovinos utilizados no experimento (Figura 4) foi definido em relação à disponibilidade de matéria seca em cada tratamento (SAN, CAN e CANM) por período experimental e também em relação ao peso corporal dos ovinos. No início do experimento o peso corporal foi de 30,87, 33,08 e 31,90 kg para os tratamentos SAN, CAN, CANM, respectivamente. No final do experimento os animais apresentaram os seguintes pesos: $33,37,34,34$ e $32,77 \mathrm{~kg}$ para os tratamentos SAN, CAN, CANM, respectivamente.

A quantidade de borregas no tratamento CANM foi diminuindo a cada período (Figura 4), pois ocorreu o superpastejo da área adubada com $150 \mathrm{~kg} / \mathrm{ha}$ de nitrogênio em alguns períodos do estudo, prejudicando a rebrota da forragem e diminuindo a quantidade de matéria verde e seca disponível do Colonião (Figura 3), além da lotação animal. Balbinoti Junior et al. (2009) relataram que quando o ambiente pastoril é bem manejado, com a utilização de fertilizantes e taxa de lotação adequada, esse pode sofrer uma serie de alterações químicas e morfológicas. Isto se reflete no aumento do crescimento tanto da parte aérea quanto no sistema radicular que demonstra-se eficiente na redução do risco de compactação de solo em função do aumento da quantidade de macroporos e matéria orgânica causando maior estabilidade da estrutura do solo (GREENWOOD e MCKENZIE, 2001), elevando o estoque de carbono no solo (CONCEIÇÃO et al., 2005) tornando o ambiente pastoril um dreno de carbono atmosférico (SILVEIRA et al., 2012). 

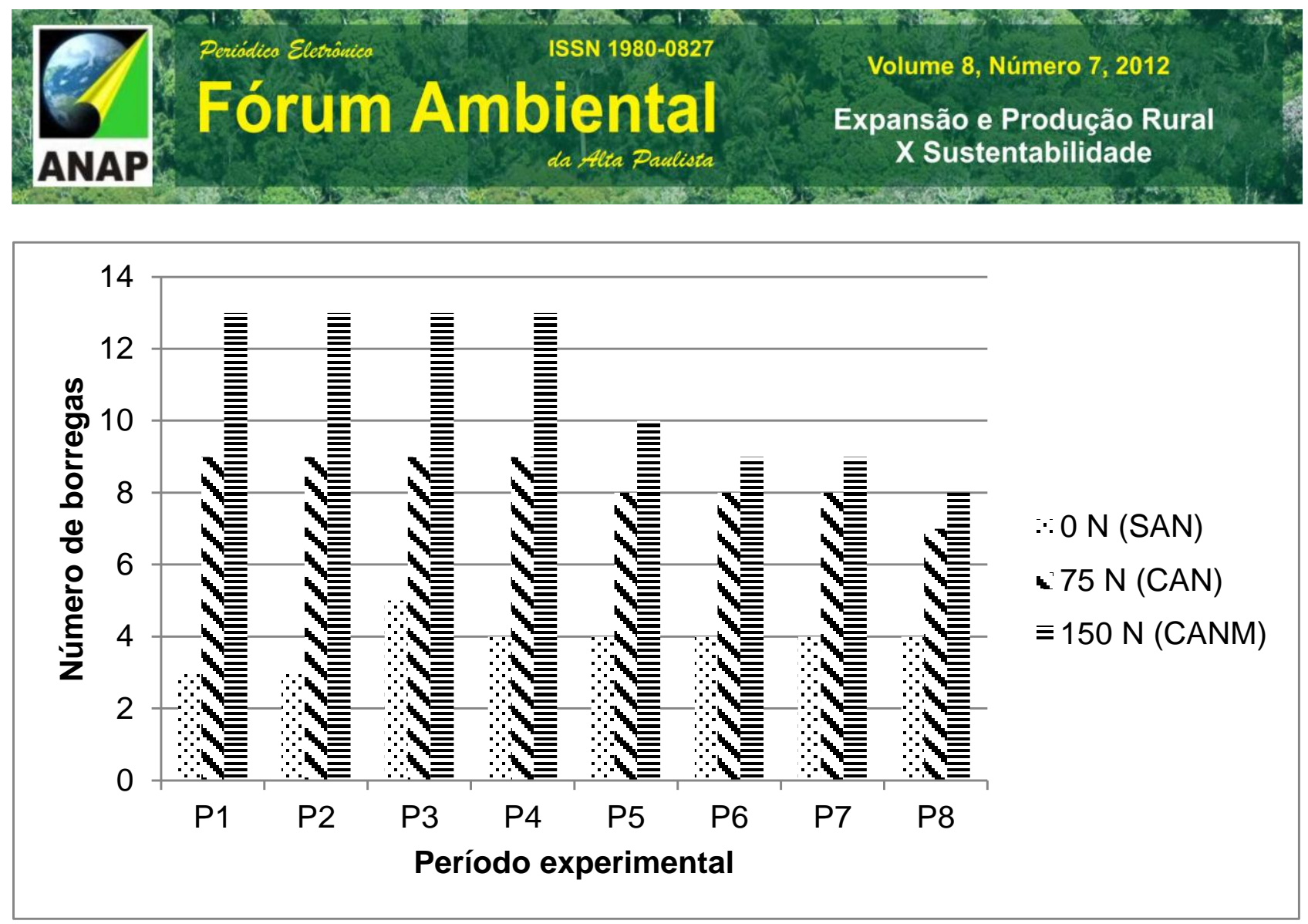

Figura 4 - Número de borregas, nos diferentes períodos experimentais, na pastagem de Colonião (Panicum maximum cv.) submetida a doses crescentes de nitrogênio ( $0 \mathrm{~kg} / \mathrm{N} / \mathrm{ha}, 75 \mathrm{~kg} / \mathrm{N} / \mathrm{ha}$ e $150 \mathrm{~kg} / \mathrm{N} / \mathrm{ha})$.

Nos sistemas de produção mais intensivos com forragens do gênero Panicum no semiárido com uso de irrigação é possível a manutenção de taxas de lotação de 60 ovinos na fase de terminação por hectare segundo Silva et al. (2007), valor este muito superior ao deste estudo (Figura 4). De acordo com os autores supracitados, os sistemas de produção nesta região são caracterizados, principalmente, pelo uso de pastagens nativas. Também nesta região, as mudanças climáticas globais, aliadas ao uso desordenado das pastagens nativas, podem determinar degradação da Caatinga com impactos negativos sobre a sustentabilidade dos sistemas de produção animal da região (SANTO et al., 2011).

No final do experimento as borregas foram pesadas e foi possível calcular o ganho de peso no período experimental $(\mathrm{kg})$ e diário $(\mathrm{g})$, o qual foi maior para os animais do tratamento SAN (2,5 kg e 44,64g/dia) em relação aos do CANM (0,87 kg e 15,53 g/dia). Quanto ao tratamento CAN apresentou valores intermediários de ganho de peso no período (1,26 kg) e diário (22,53 g/dia) em relação aos do SAN e CANM (Figura 5). 

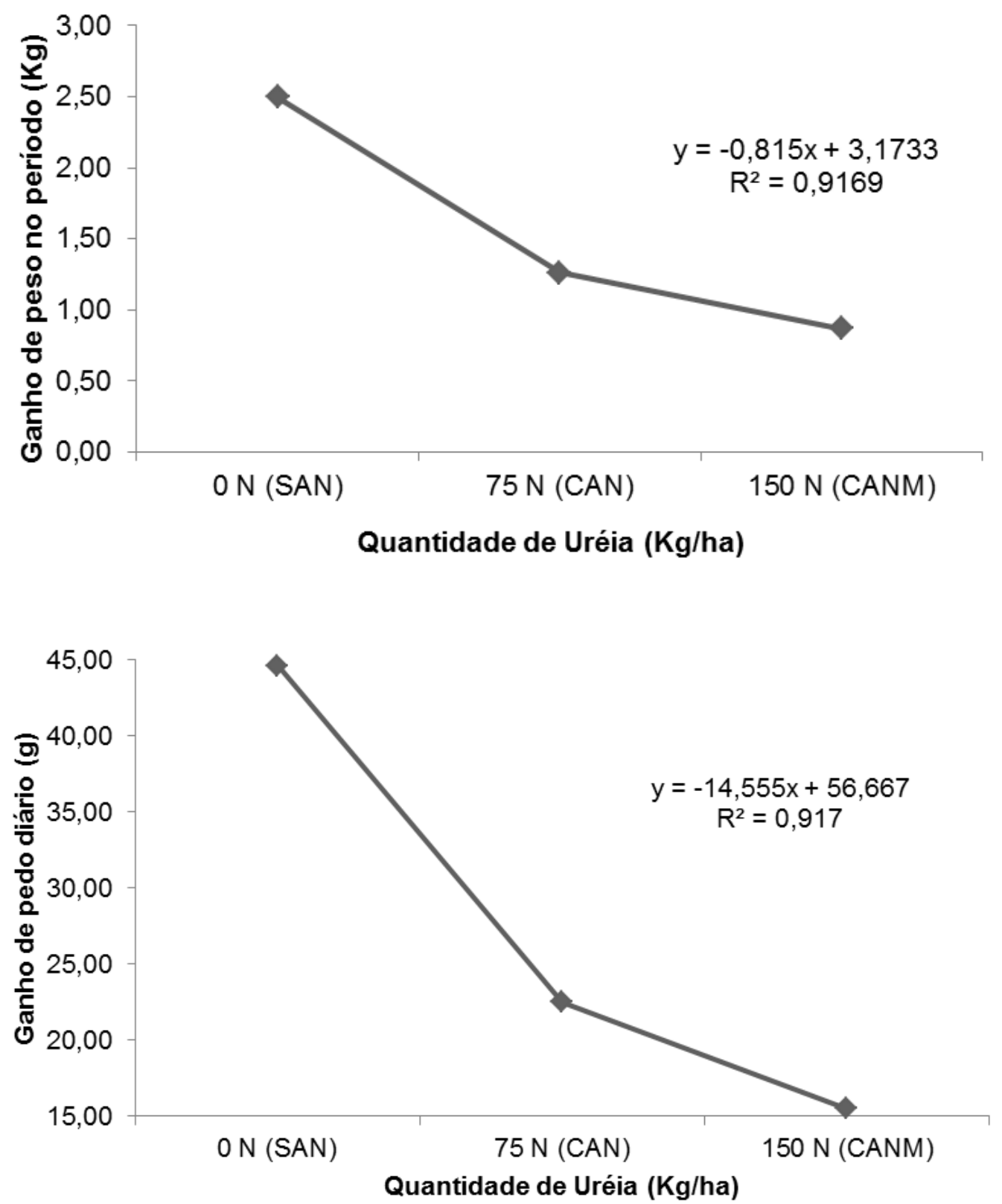

Figura 5 - Ganho de peso no período experimental $(\mathrm{kg})$ e diário $(\mathrm{g})$ de borregas em pastagem de Colonião (Panicum maximum cv.), submetida a doses crescentes de nitrogênio $(0 \mathrm{~kg} / \mathrm{N} / \mathrm{ha}, 75 \mathrm{~kg} / \mathrm{N} / \mathrm{ha}$ e 150 $\mathrm{kg} / \mathrm{N} / \mathrm{ha})$.

Voltolini et al. (2011) relataram taxas de lotação de 10 cordeiros/ha e ganhos de $64 \mathrm{~g}$ animal/dia para animais com peso corporal de 21,14 $\mathrm{kg}$ mantidos exclusivamente em pastagens de capim-bufel durante o período seco do ano. Porém este ganho de peso 
obtido por estes autores foi de cordeiros suplementados com concentrado em $1 \%$ do peso corporal e os animais que receberam $0,33 \%$ de concentrado apresentaram ganho de peso de $48 \mathrm{~g}$ dia, semelhantes ao deste estudo para o tratamento SAN (Figura 5).

\section{CONCLUSÃO}

A adubação nitrogenada proporcionou maior quantidade de forragem em relação à pastagem não adubada, portanto há possibilidade do sistema de produção apresentar maior produtividade sem a necessidade de desmatamento de novas áreas. A adubação nitrogenada de pastagem permite a sustentabilidade do ambiente em áreas de pastejo de animais domesticados pelo homem, os quais são produzidos para fornecerem alimento ao seres humanos.

Observou-se que à medida que aumentou a lotação animal por área o ganho de peso foi inferior, portanto é necessário ajustar a quantidade de animais de forma adequada à área, para que não ocorra o superpastejo e consequentemente prejudique a rebrota da forragem.

\section{REFERÊNCIAS}

BALBINOTI JUNIOR, A.A. et al. Integração lavoura pecuária: intensificação de uso de áreas agrícolas. Ciência Rural, Santa Maria, v.39, n.6, p.1925-1933, 2009.

BARCELLOS, A.O. et al. Sustentabilidade da produção animal baseada em pastagens consorciadas e no emprego de leguminosas exclusivas, na forma de banco de proteína, nos trópicos brasileiros. Revista Brasileira de Zootecnia, Viçosa, v.37, suplemento especial, p.51-67, 2008.

CONCEIÇÃO, P.C. et al. Qualidade do solo em sistemas de manejo avaliada pela dinâmica da matéria orgânica e atributos relacionados. Revista Brasileira de Ciência do Solo, Viçosa, v.29, n.5, p.777-788, 2005.

GASTALDI, K.A. Taxas de lotação influenciando a produção ovina. 1996. 118f. Trabalho de conclusão de curso (Graduação em Zootecnia) - Universidade Estadual Paulista, Faculdade de Ciências Agrárias e Veterinárias, Jaboticabal, 1996. 
GREENWOOD, K.L.; McKENZIE, B.M. Grazing effects on soil physical properties and the consequences for pastures: a review. Australian Journal of Experimental Agriculture, Collingwood, v. 41, n. 8, p. 1231-1250, 2001.

HERNANDEZ, F.B.T.; LEMOS FILHO, M.A.F.; BUZETTI, S. Software HIDRISA e o balanço hídrico de Ilha Solteira. Ilha Solteira: UNESP/FEIS/Área de Hidráulica e Irrigação, 1995. 45p.

MOREIRA, L.M. et al. Produção animal em pastagem de capim-braquiária adubada com nitrogênio. Arquivo Brasileiro de Medicina Veterinária e Zootecnia, Belo Horizonte, v.63, n.4, p.914-921, 2011.

MOTT, G.O.; LUCAS, H.L. The design, conduct and interpretation of grazing trials on cultivated and improved pastures. In: INTERNATIONAL GRASSLAND CONGREES, 6., 1952, State College. Proceedings... State College: Pennsylvania State College Press, 1952. p.1380-1385.

PAULINO, V.T.; TEIXEIRA, E.M.L.C. Sustentabilidade de pastagens - Manejo adequado como medida redutora da emissão de gases de efeito estufa. Disponível em: <http://www.iz.sp.gov.br/artigo.php?id=120>. Acesso em: 27 set. 2012.

SANTOS, P.M. et al. Mudanças Climáticas Globais e a Pecuária: Cenários Futuros para o Semiárido Brasileiro. Revista Brasileira de Geografia Física, Recife, v.6, p.1176-1196, 2011.

SAS Institute Inc. Statistical Analysis System user's guide. Version 9.0 ed. Cary, 2002. 513p.

SILVA, R. G. et al. Aspectos comportamentais e desempenho produtivo de ovinos mantidos em pastagens de capim-tanzânia manejado sob lotação intermitente. Ciência Animal Brasileira, Goiânia, v. 8, n.4, p. 609-620, 2007.

SILVA, T. G. F. et al Cenários de mudanças climáticas B1 e A1F1 e seus impactos na produção leiteira em estados nordestinos. Revista Brasileira de Engenharia Agrícola e Ambiental, Campina Grande, v.14, n.8, p.863-870, 2010.

SILVEIRA, E.R. et al. Intensidade de pastejo e adubação nitrogenada na massa seca de aveia e produtividade do milho na integração lavoura-pecuária. Semina: Ciências Agrárias, Londrina, v. 33, n.4, p. 1323-1332, 2012.

VOLTOLINI, T. V. et al. Concentrate levels for lambs grazing on bufel grass. Revista Ciência Agronômica, Fortaleza, v. 42, n.1, p. 216-222, 2011.

WERNER, J.C. et al. Adubação de Pastagens. In: SIMPÓSIO SOBRE MANEJO DA PASTAGEM, 18., 2001, Piracicaba. Anais... Piracicaba: Fealq, 2001. p. 129-156. 